Purdue University Purdue e-Pubs

$12-1-2001$

\title{
A comparative analysis of studies on heat transfer and fluid flow in microchannels
}

Choondal B. Sobhan

Purdue University

Suresh Garimella

School of Mechanical Engineering, sureshg@purdue.edu

Follow this and additional works at: http://docs.lib.purdue.edu/nanodocs

Sobhan, Choondal B. and Garimella, Suresh, "A comparative analysis of studies on heat transfer and fluid flow in microchannels" (2001). Other Nanotechnology Publications. Paper 17.

http://docs.lib.purdue.edu/nanodocs/17

This document has been made available through Purdue e-Pubs, a service of the Purdue University Libraries. Please contact epubs@purdue.edu for additional information. 


\section{A COMPARATIVE ANALYSIS OF STUDIES ON HEAT TRANSFER AND FLUID FLOW IN MICROCHANNELS}

\section{Choondal B. Sobhan and Suresh V. Garimella}

School of Mechanical Engineering, Purdue University, West Lafayette, Indiana, USA

The extremely high rates of heat transfer obtained by employing microchannels makes them an attractive alternative to conventional methods of heat dissipation, especially in applications related to the cooling of microelectronics. A compilation and analysis of the results from investigations on fluid flow and heat transfer in micro- and mini-channels and microtubes in the literature is presented in this review, with a special emphasis on quantitative experimental results and theoretical predictions. Anomalies and deviations from the behavior expected for conventional channels, both in terms of the frictional and heat transfer characteristics, are discussed.

Among the novel methods for thermal management of the high heat fluxes found in microelectronic devices, microchannels are the most effective at heat removal. The possibility of integrating microchannels directly into the heat-generating substrates makes them particularly attractive, since thermal contact resistances may be avoided. The two important objectives in electronics cooling-minimization of the maximum substrate temperature and reduction of substrate temperature gradients—can be achieved by the use of microchannels.

A large number of recent investigations have undertaken to study the fundamentals of microchannel flow, as well as to compare the flow and heat transfer characteristics of microchannels with conventional channels. A comprehensive review of these investigations conducted over the past decade is presented here in concise tabular form.

Predictive correlations have also been proposed in the literature, based on experimental investigations on liquid and gas flow in microchannels. Various combinations of channel size, pitch, and substrate material have been considered. Generally, these correlations have been cast in the same forms as conventional relationships for larger-diameter tubes and channels, but have included modified coefficients. A comparative study of the correlations for single-phase flow is presented in this review.

Address correspondenc e to Prof. Suresh V. Garimella, Purdue University, 1288 Mechanical Engineering Building, West Lafayette, IN 47907-1288, USA. E-mail: sureshg@ecn.purdue.ed u 


\begin{tabular}{|c|c|c|c|}
\hline \multicolumn{4}{|c|}{ NOMENCLATURE } \\
\hline$A_{c}$ & cross-sectional area & $\operatorname{Pr}$ & Prandtl number \\
\hline$A_{s}$ & surface area & $\Delta P$ & pressure drop \\
\hline$B$ & slot width & $q_{\mathrm{m} ; \mathrm{p}}$ & CHF based on heated channel area \\
\hline$c_{a}$ & acoustic velocity & $Q$ & volumetric flow rate \\
\hline$C$ & coolant heat capacity & $R_{\text {th1D }}$ & thermal resistance from 1-D analysis \\
\hline$D$ & diameter & $R_{\mathrm{th} 3 \mathrm{D}}$ & thermal resistance from 3-D analysis \\
\hline$D_{h}$ & hydraulic diameter & $\mathrm{Re}$ & Reynolds number \\
\hline$f$ & friction factor & $T_{i}$ & inlet temperature \\
\hline$G$ & mass velocity ( $\equiv m$, mass flux $)$ & $t$ & tube wall thickness \\
\hline$h_{f g}$ & latent heat of vaporizaton & $v$ & inlet velocity \\
\hline$H^{\circ}$ & height (depth) of microchannel & $W$ & width of microchannel \\
\hline$k_{c}$ & coolant thermal conductivity & We & Weber number \\
\hline$L$ & length & $x$ & distance from stagnation point \\
\hline $\mathrm{Nu}$ & Nusselt number & $\mu$ & dynamic viscosity \\
\hline $\mathrm{Nu}_{\mathrm{Gn}}$ & Nusselt number (Gnielinski correlation) & $v$ & kinematic viscosity \\
\hline$P$ & channel pitch & $\rho$ & density \\
\hline
\end{tabular}

\section{REVIEW OF THE LITERATURE}

Studies on microchannel flows in the past decade are categorized into various topics and summarized in Table 1. The literature survey extends over a wide range of topics such as measurement and estimation of friction factor and heat transfer in microchannels and small-diameter tubes, comparison with flow in conventional channels, investigation of single-phase, boiling, and two-phase flows in microchannels, minichannels, and small tubes, gas flow in microchannels, analytical studies on microchannel flows, and design and testing of microchannel heat sinks for electronics cooling. For each study, key descriptors of the cooling configuration and the primary observations are included.

\section{QUANTITATIVE COMPARISONS}

A comparative study of correlations for single-phase flow and heat transfer in microchannels proposed by various investigators is presented in this section. Correlations for friction factor and heat transfer in the laminar and turbulent regimes are compared and contrasted with conventional correlations for macrotubes and channels. Details of each of the studies discussed in this section are available in Table 1.

\section{Friction Correlations}

Correlations for friction factor have been proposed based on experiments with nitrogen and water as working fluids [3, 9, 36] in trapezoidal and rectangular channels and microtubes. Peng et al. [13] analyzed water flow in rectangular channels to obtain correlations for various combinations of the channel hydraulic diameter and channel pitch in rectangular channels for laminar and turbulent flow. A plot of the friction factor correlations proposed for laminar and turbulent flow in microchannels is shown in Figure 1. The graph shows the product of friction factor and Reynolds number $(f \cdot \operatorname{Re})$ plotted against the Reynolds number. Conventional correlations are also included for comparison: the Blasius correlation $\left(f=0.140 \mathrm{Re}^{-0.182}\right)$ is used for turbulent flow, while for 


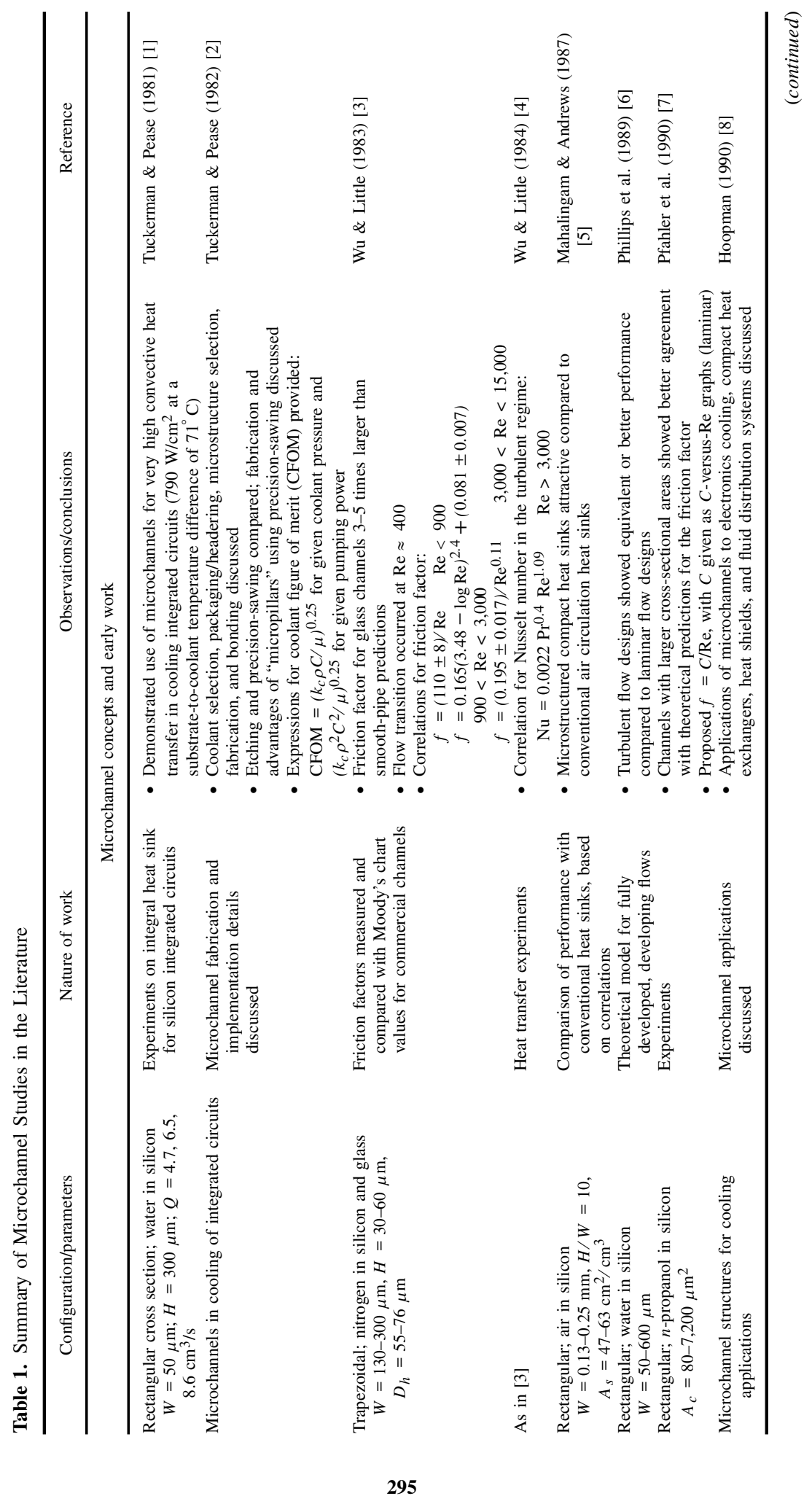




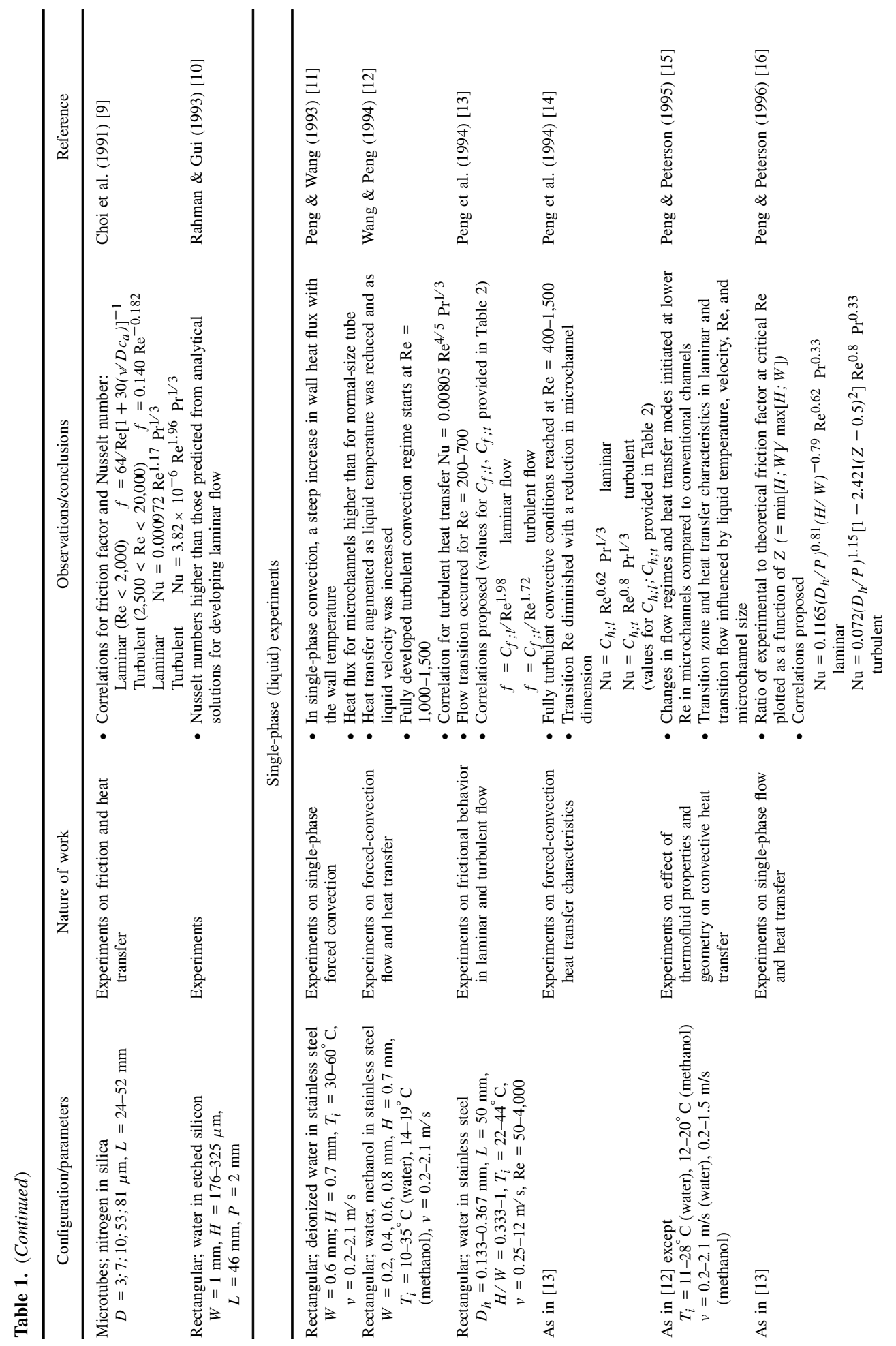


$\Xi$
$\Xi$
0
2
0
0
0
00
00
0
2
2
00
0
0
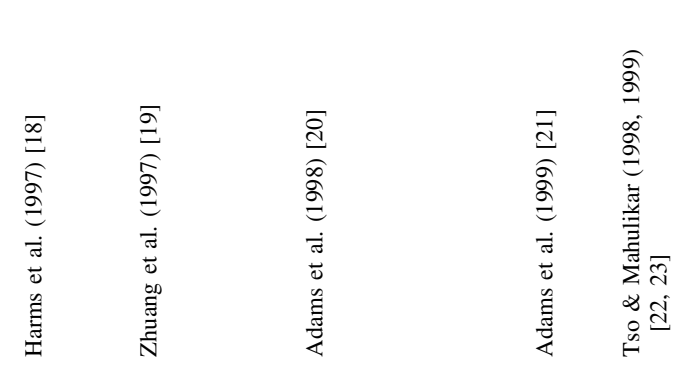

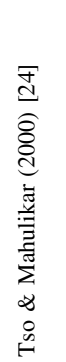

$\stackrel{3}{\underline{a}}$

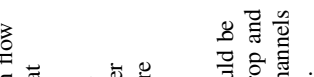

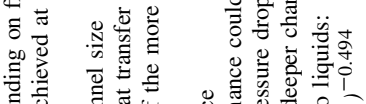

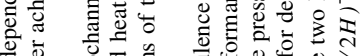

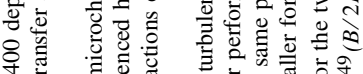

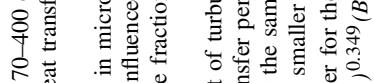

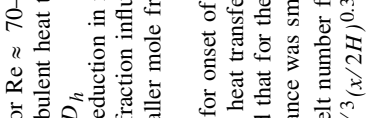

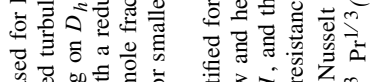

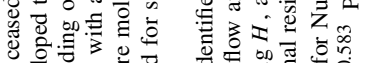

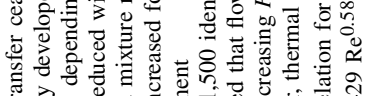

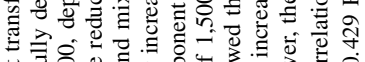

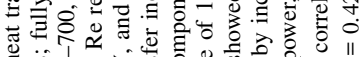

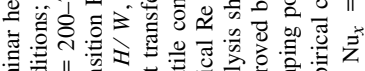

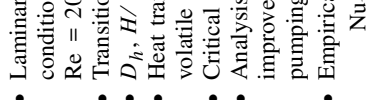
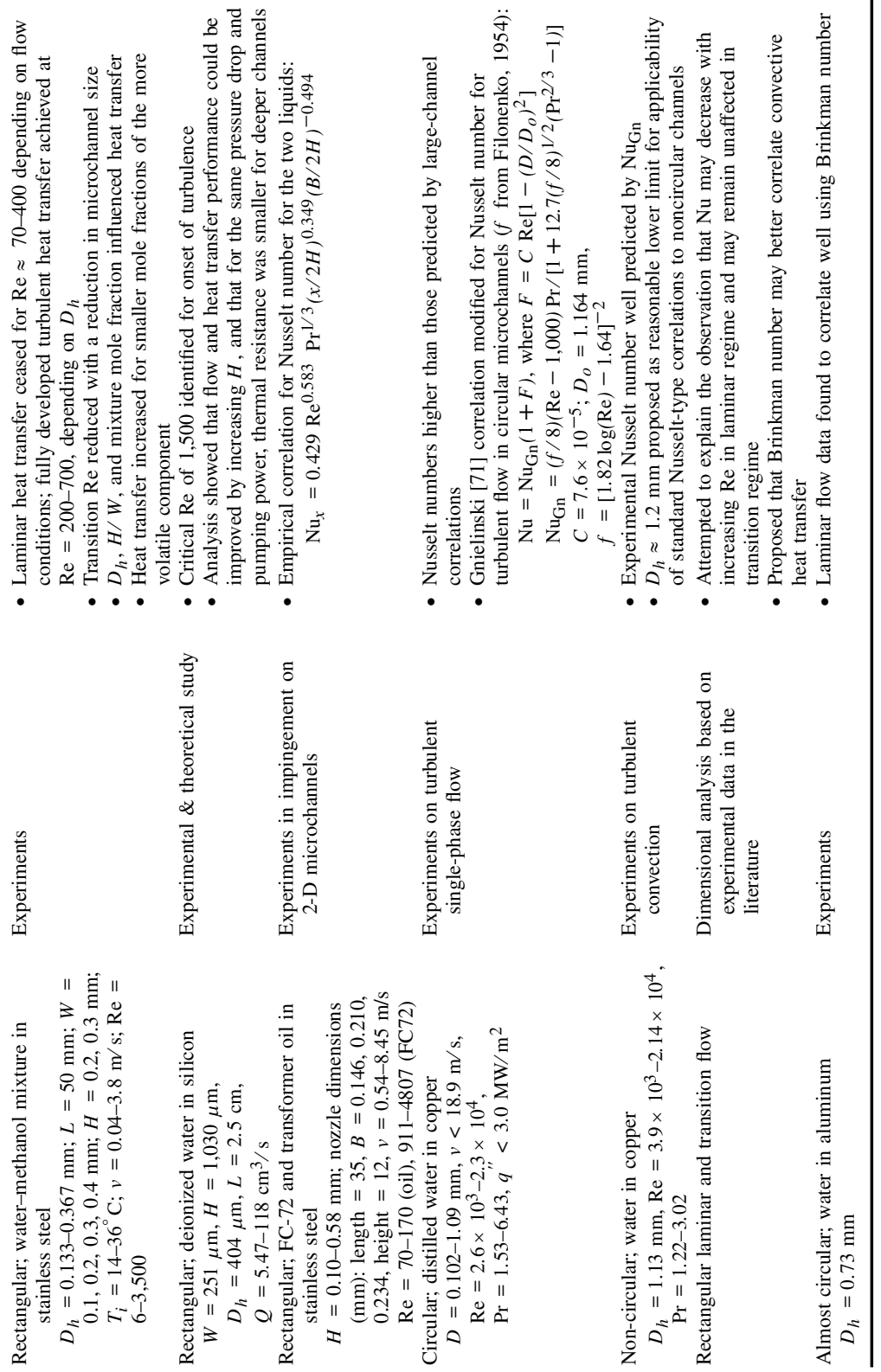


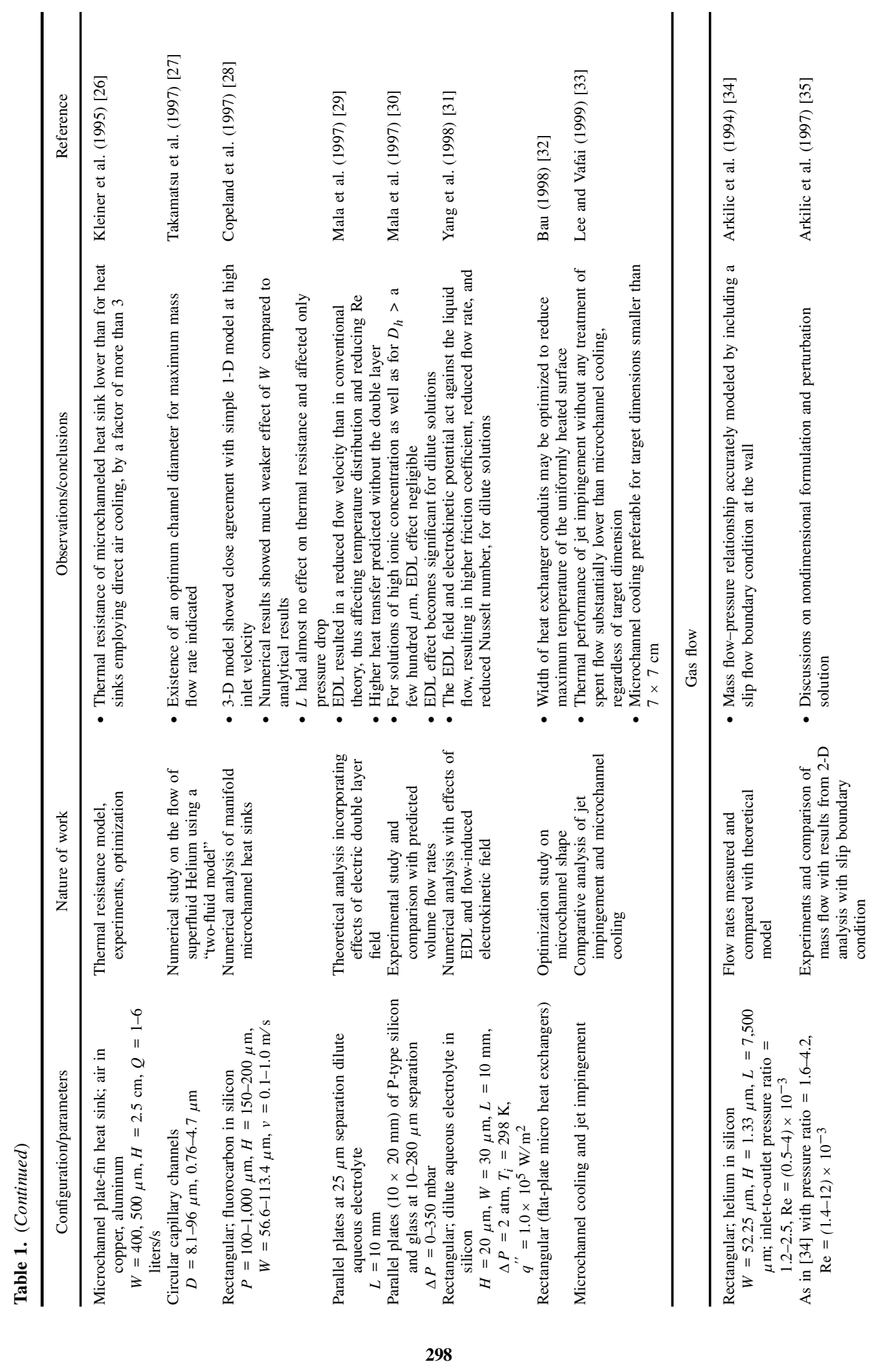




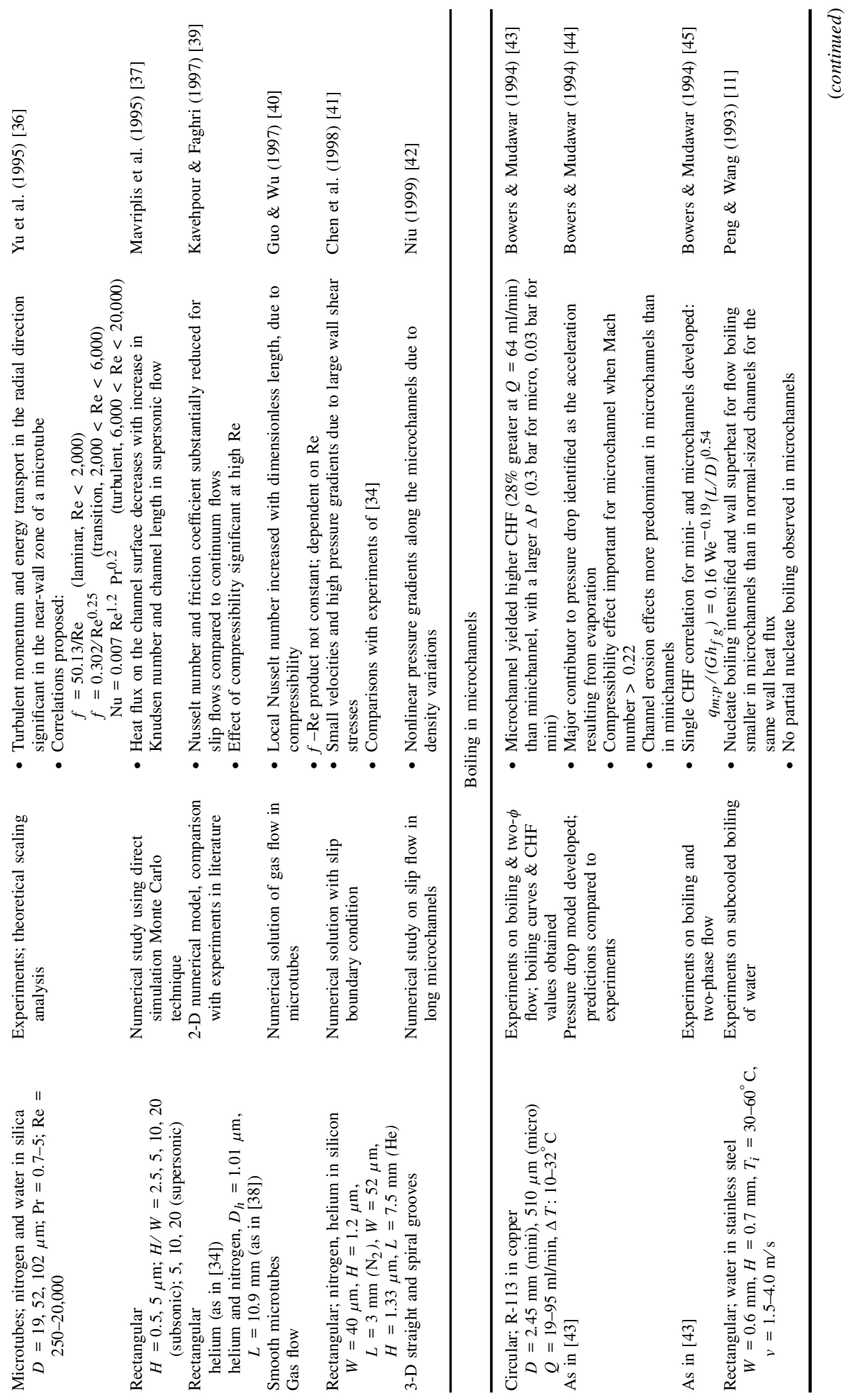




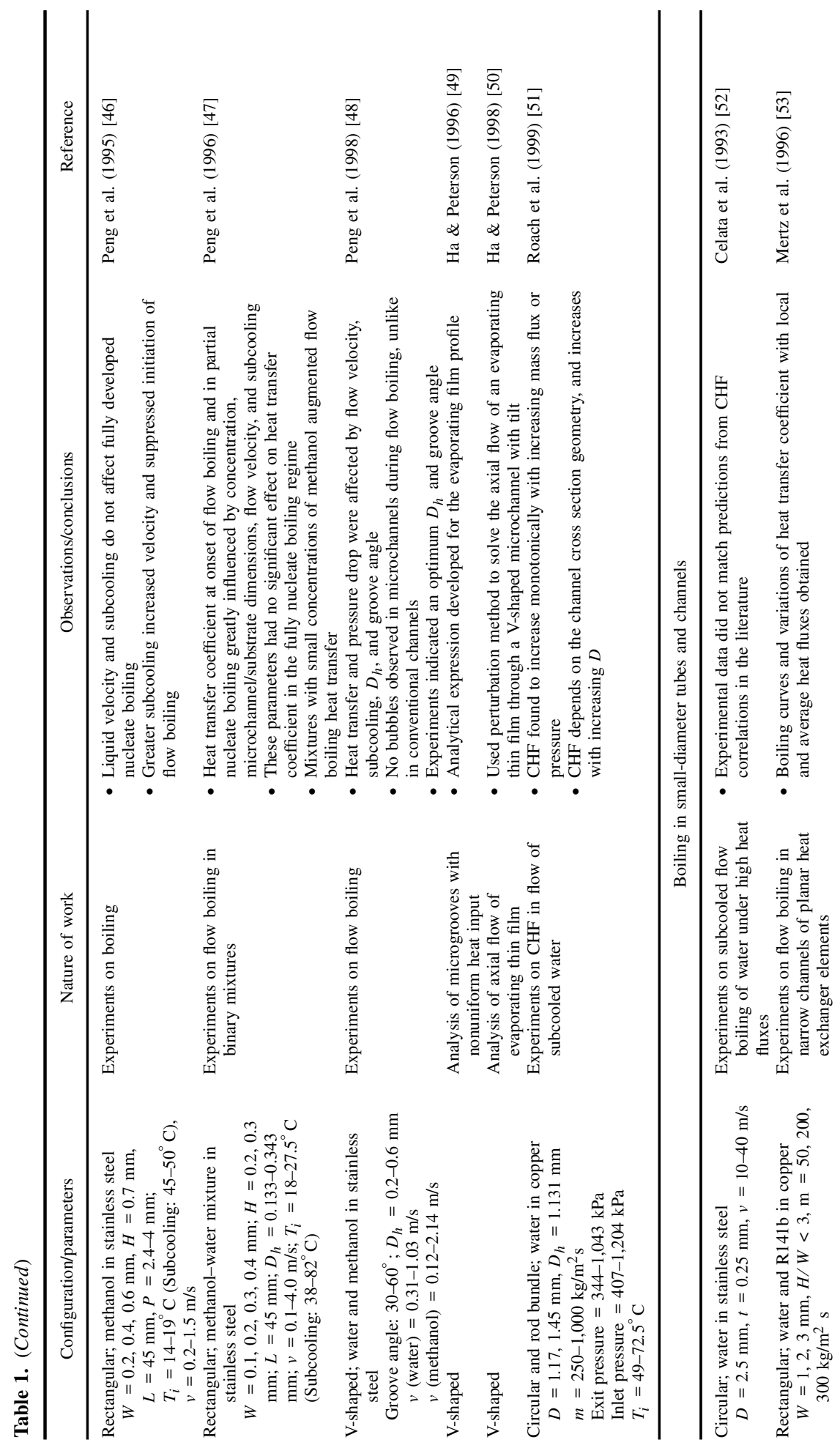




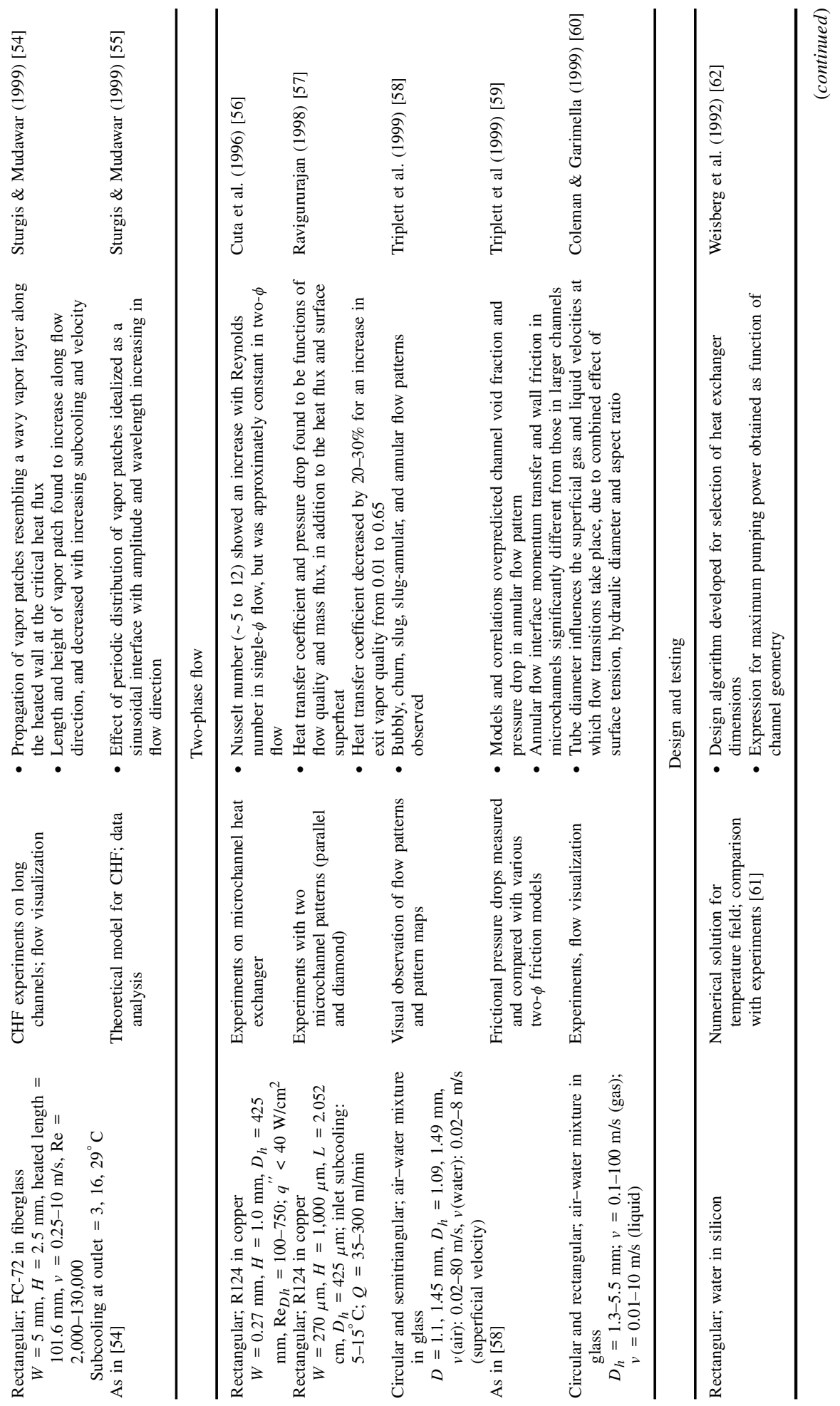




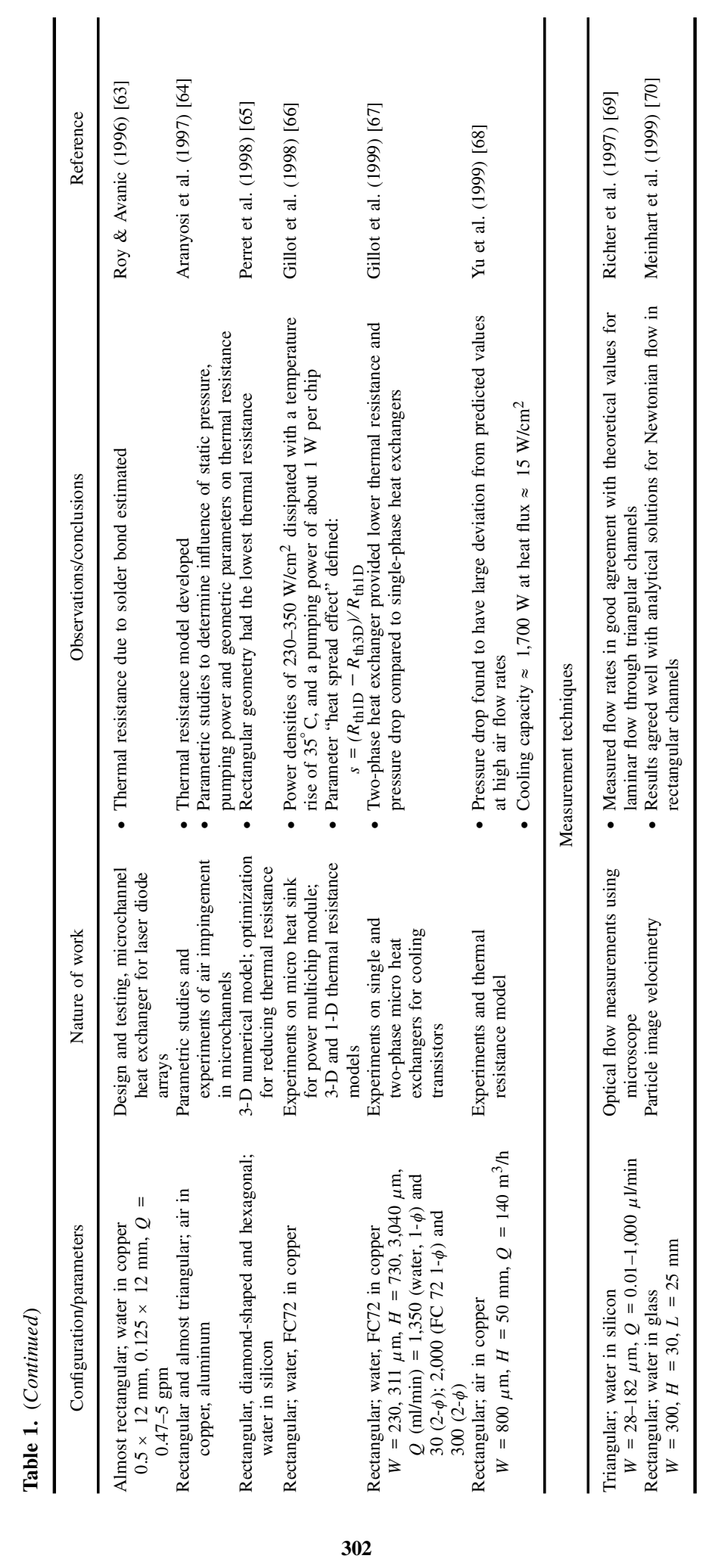




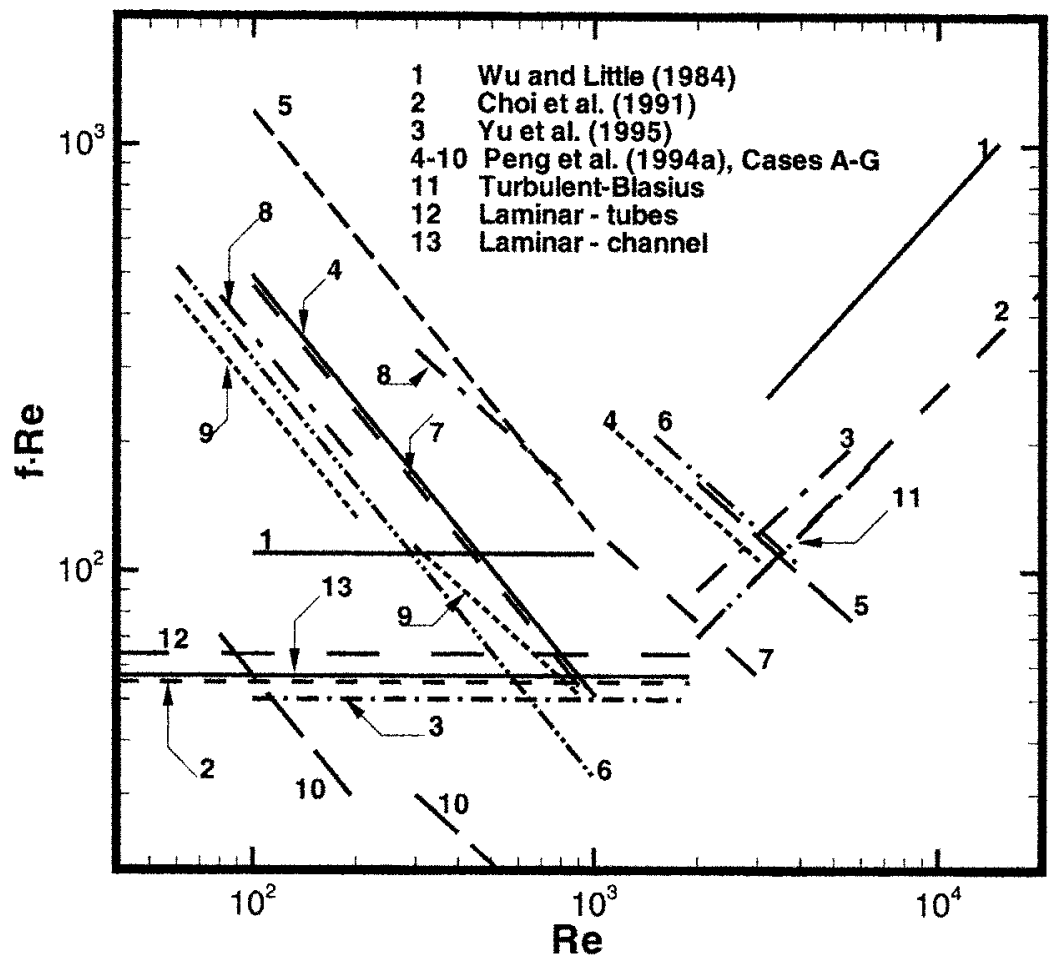

Figure 1. Friction-factor predictions from the literature for microchannels and conventional channels, in the laminar and turbulent regimes.

laminar flow, circular-pipe $(f=64 / \mathrm{Re})$ and square-channel predictions $(f=57 / \mathrm{Re})$ are shown. The $f \cdot \operatorname{Re}$ product is independent of Reynolds number for laminar flow in conventional channels. In the turbulent regime, the friction factor is almost independent of the Reynolds number $(f \cdot \operatorname{Re}$ increases linearly with $\mathrm{Re})$. The predictions in the literature for microchannels may be analyzed with greater ease by considering the laminar and turbulent regions separately.

Predictions of $f \cdot \operatorname{Re}$ in the laminar regime are shown in Figure 2. The correlations of $\mathrm{Wu}$ and Little [3], Choi et al. [9], and Yu et al. [36] predict constant values of $f \cdot \operatorname{Re}$, with the magnitude of this product being greater than for conventional channels in $\mathrm{Wu}$ and Little (110), and lower in Choi et al. [55] and Yu et al. [50], respectively. Predictions from Peng et al. [13] for water flow in rectangular microchannels (see Table 1 for details) show an altogether different trend: in all cases, $f \cdot$ Re decreases with an increase in the Reynolds number. For cases A, B, and C from Peng et al. (in which $D_{h} \geq 267 \mu \mathrm{m}$ ), the laminar regime extends to $\mathrm{Re} \approx 700$, whereas for cases $\mathrm{E}, \mathrm{F}$, and $\mathrm{G}\left(D_{h}<200 \mu \mathrm{m}\right)$, the onset of turbulence occurs as early as $\mathrm{Re}=300$. (As in the original work, the laminar plots for cases A-D are extended until $\mathrm{Re}=1,000)$. While the slopes of the curves for all test cases are identical $\left(\operatorname{Re}^{-0.98}\right)$, the magnitude of $f \cdot \operatorname{Re}$ is highest for the largest microchannels $\left(D_{h}\right)$ and lowest for the smallest.

The friction correlations in the turbulent regime are compared with conventional correlations in Figure 3. Predictions for nitrogen flow from Choi et al. agree very well 


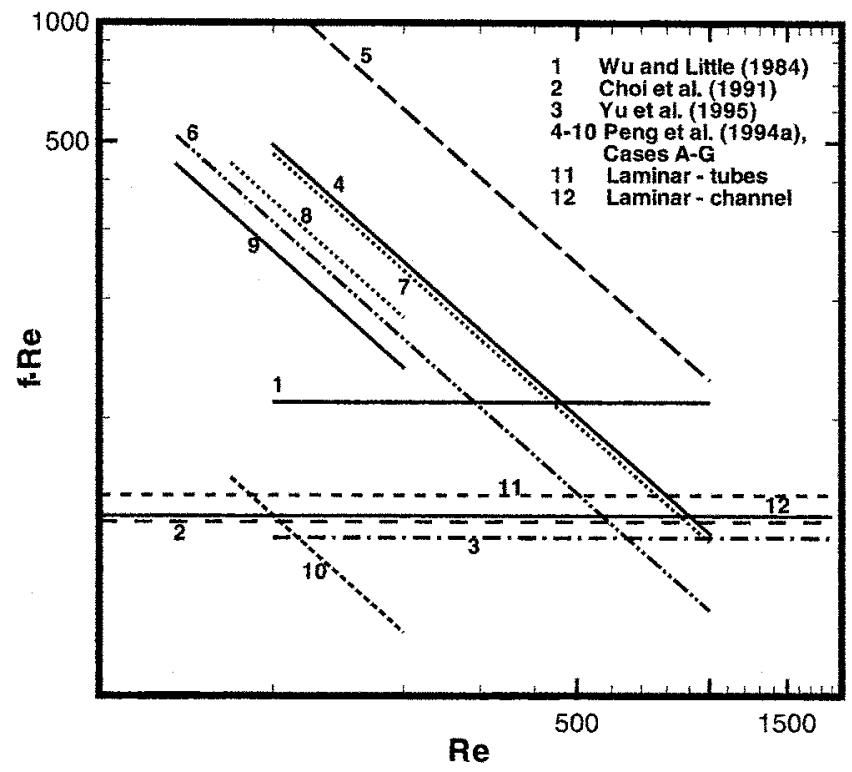

Figure 2. Friction-factor predictions in the laminar regime.

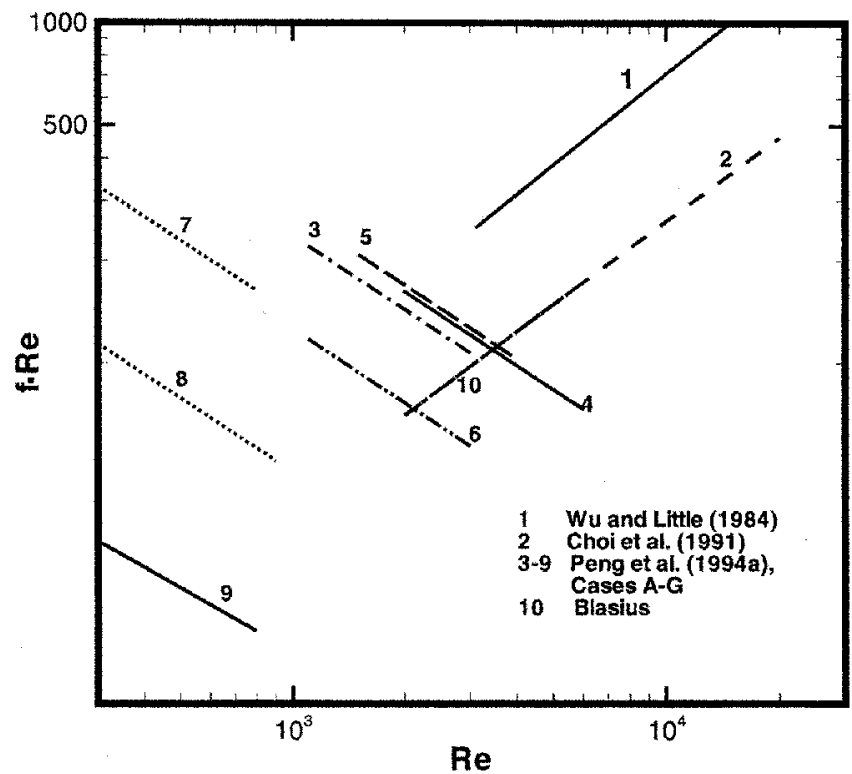

Figure 3. Friction-factor predictions in the turbulent regime. 
Table 2. Microchannel configurations and coefficients from Peng et al. [13, 14]

\begin{tabular}{ccccccccccc}
\hline Case & $W(\mathrm{~mm})$ & $H(\mathrm{~mm})$ & $L(\mathrm{~mm})$ & $D_{h}(\mathrm{~mm})$ & $H / W$ & $\operatorname{Re} \mathrm{cr}$ & $C_{f ; l}$ & $C_{f ; t}$ & $C_{h ; l}$ & $C_{h ; t}$ \\
\hline $\mathrm{A}$ & 0.4 & 0.3 & 50 & 0.343 & 0.75 & 700 & 44800 & 34200 & 0.058 & 0.0134 \\
$\mathrm{~B}$ & 0.3 & 0.3 & 50 & 0.3 & 0.1 & 700 & 109000 & 38600 & 0.0384 & 0.00726 \\
$\mathrm{C}$ & 0.4 & 0.2 & 50 & 0.267 & 0.5 & 700 & 28600 & 40400 & 0.0426 & 0.0166 \\
$\mathrm{D}$ & 0.3 & 0.2 & 50 & 0.24 & 0.667 & 400 & 42600 & 18200 & 0.0472 & $*$ \\
$\mathrm{E}$ & 0.2 & 0.2 & 50 & 0.2 & 1 & 200 & 32400 & 20100 & 0.0468 & 0.00696 \\
$\mathrm{~F}$ & 0.3 & 0.1 & 50 & 0.15 & 0.333 & 200 & 24200 & 6920 & 0.0104 & 0.00483 \\
$\mathrm{G}$ & 0.2 & 0.1 & 50 & 0.133 & 0.5 & 200 & 5200 & 1820 & 0.0285 & 0.00939 \\
\hline
\end{tabular}

with conventional results; the $\mathrm{Wu}$ and Little correlation is similar to these two in its trend of variation, but the predicted values are much higher in magnitude. The correlations of Peng et al. [13] for water flow again exhibit a very different trend: in all cases, $f \cdot \operatorname{Re}$ decreases with an increase in Reynolds number (as $\operatorname{Re}^{-0.72}$ ), in contradiction to conventional correlations. The onset of turbulence is also seen to occur much earlier for the microchannels studied by Peng et al. Another observation of interest in Figure 3 is that the $f \cdot \operatorname{Re}$ values predicted by Peng et al. decrease in magnitude as the channel hydraulic diameter decreases; the drop in $f \cdot \operatorname{Re}$ with $D_{h}$ is very steep when $D_{h}$ becomes smaller than $200 \mu \mathrm{m}$.

\section{Heat Transfer Correlations}

Correlations for the average Nusselt number in microchannels in terms of the Reynolds and Prandtl numbers have been proposed in the literature for laminar and turbulent regimes, based on experiments with a range of fluid-substrate combinations, channel dimensions, and configurations, as summarized in Table 1.

Heat transfer correlations for nitrogen flow $[4,9,36]$, water flow in rectangular microchannels $[12,14,16]$, water flow in circular microchannels [20,36], and methanol in rectangular channels [12] are considered for comparison. Figure 4 shows a composite plot of predicted values of $\mathrm{Nu} / \mathrm{Pr}^{0.33}$ as a function of Reynolds number from the correlations in these studies. Conventional channel correlations are also included for comparison: the Dittus-Boelter correlation for turbulent flow in conventional channels, and for laminar flow, $\mathrm{Nu}_{D h}=1.86\left(\operatorname{Re}_{D h} \operatorname{Pr}\right)^{0.33}\left(D_{h} / L\right)^{0.33}$; a sample set of parameters $(L=50 \mathrm{~mm}$ and $D_{h}=0.24 \mathrm{~mm}$ ) is used to compute values from this correlation. A significant amount of scatter is seen in these plots, as was true for predictions of friction factor, with the predictions of Choi et al. [9] and Yu et al. [36] being among the highest in the turbulent regime. All predictions reflect an increase in Nusselt number with increasing Re.

The heat transfer correlations are again considered separately in the laminar and turbulent regimes in Figures 5 and 6, respectively. The end of the laminar regime was identified to be at quite different Reynolds numbers in the studies considered, as noted with the friction factor predictions. The dependence of Nusselt number on Reynolds number is stronger in all the microchannel predictions when compared to conventional results, as indicated by the steeper slopes of the former; Choi et al. [9] predict the strongest variation of Nusselt number with Re. Also, the predictions for all cases from Peng et al. fall below those for a conventional channel. 


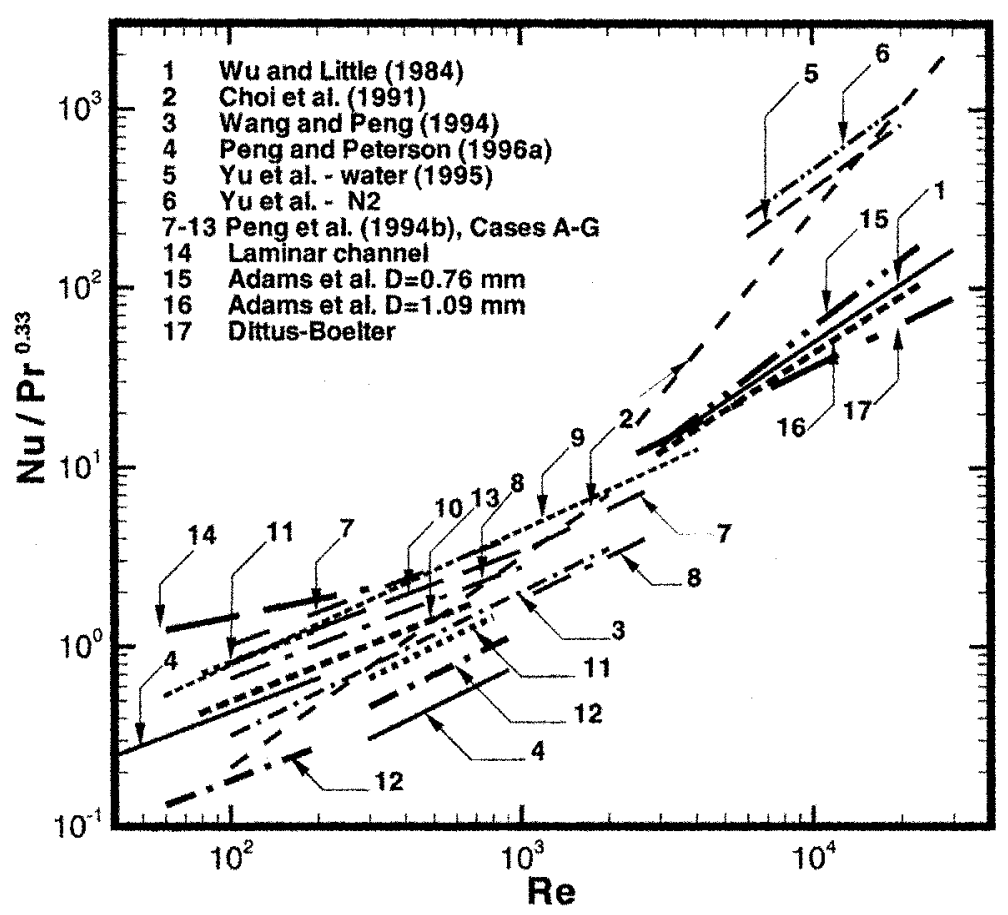

Figure 4. Heat transfer predictions from the literature for microchannels and conventional channels, in the laminar and turbulent regimes.

In the turbulent regime (Figure 6), the predictions of all investigators with the exception of Peng et al. [14] and Peng and Peterson [16] fall above the conventional channel values. In particular, Adams et al. 20] and $\mathrm{Wu}$ and Little [4] lie in one group. The predictions of Choi et al. [9] and Yu et al. [36] are also somewhat comparable, and lie in a different group. It may be noted that these groups are not divided by fluid type (since both groups include results for nitrogen and water) or by microchannel dimensions. The rectangular microchannels of different dimensions (Table 1) considered in Peng et al. [14] exhibit a large variation in predicted Nusselt numbers. In all these results, as well as for Peng and Peterson [16], the predicted values lie below those from the DittusBoelter correlation. Turbulent heat transfer predictions for case D are not included in this comparison since it appears that the value of $C_{h ; t}$ for this case may have been erroneously listed in [14] as 0.0926, and instead, should have been 0.00926. This latter value would more closely match other values for $C_{h ; t}$, and would also result in the predictions for case D lying in the same group as cases A, B, and C.

\section{CONCLUSION}

A comparative study of the results of investigations in the literature on flow and heat transfer in microchannels has been compiled in tabular form, under various research topics. Correlations for single-phase friction factor and Nusselt number proposed by various investigators based on their experiments have been compared and contrasted 


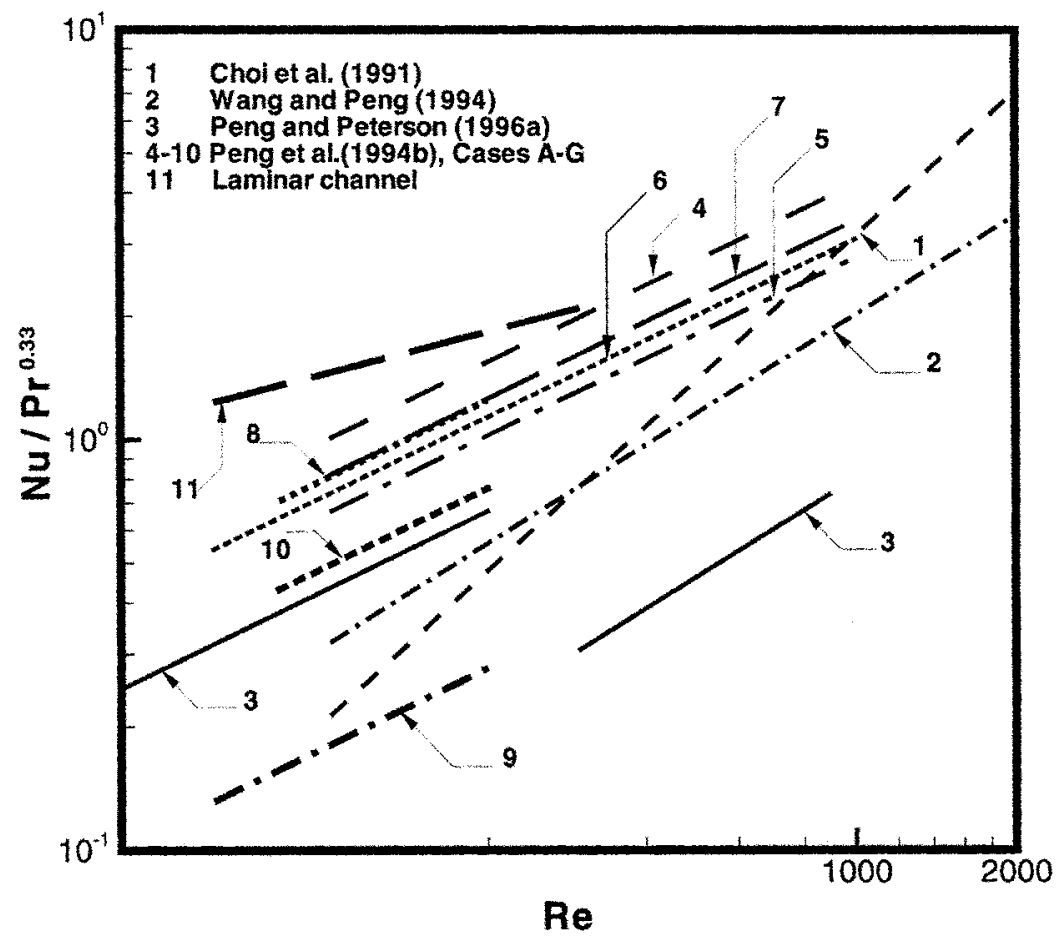

Figure 5. Heat transfer predictions in the laminar regime.

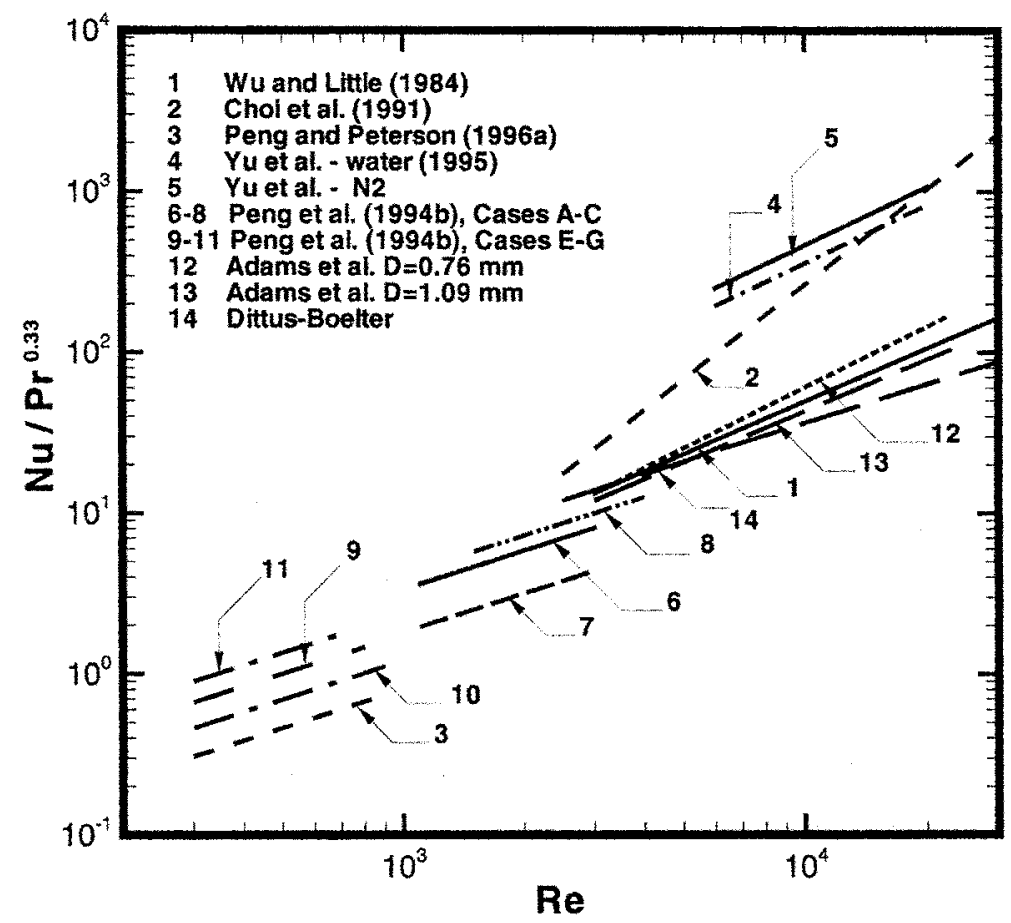

Figure 6. Heat transfer predictions in the turbulent regime. 
with conventional correlations for larger, conventional tubes and channels in the laminar and turbulent flow regimes. A number of working fluid and substrate combinations, and shapes and configurations of the microchannels are included in this comparison. Little agreement is seen between the predictions of different investigators. The results are also not seen to be distinguished by fluid or substrate type or by microchannel dimensions and shapes.

The comparative study presented here points to differences between the flow and heat transfer in microchannels and that in channels of conventional sizes. However, the information in the literature thus far does not point to unequivocal trends of variation or reasons for such trends. There is no evidence that continuum assumptions are violated for the microchannels tested, most of which have hydraulic diameters of $50 \mu \mathrm{m}$ or more. As such, analyses based on Navier-Stokes and energy equations would be expected to model the phenomena observed adequately, as long as the experimental conditions and measurements are identified and simulated correctly. The discrepancies in predictions may very well be due to entrance and exit effects, differences in surface roughness in the different microchannels investigated, nonuniformity of channel dimensions, nature of the thermal and flow boundary conditions, and uncertainties and errors in instrumentation, measurement, and measurement locations. Given the diversity in the results in the literature, a reliable prediction of the heat transfer rates and pressure drops in microchannels is not currently possible for design applications such as microchannel heat sinks. There is a clear need for additional systematic studies which carefully consider each parameter influencing transport in microchannels.

\section{REFERENCES}

1. D. B. Tuckerman and R. F. W. Pease. High-Performance Heat Sinking for VLSI, IEEE Electron. Device Lett., vol. EDL-2, pp. 126-129, 1981.

2. D. B. Tuckerman and R. F. W. Pease. Ultrahigh Thermal Conductance Microstructures for Cooling Integrated Circuits, Procs. 32nd Electronics Components Conf., IEEE, EIA, CHMT, pp. 145-149, 1982.

3. P. Y. Wu and W. A. Little. Measurement of Friction Factor for the Flow of Gases in Very Fine Channels Used for Micro Miniature Joule Thompson Refrigerators, Cryogenics, vol. 23, pp. 273-277, 1983.

4. P. Y. Wu and W. A. Little. Measurement of the Heat Transfer Characteristics of Gas Flow in Fine Channel Heat Exchangers for Micro Miniature Refrigerators, Cryogenics, vol. 24, pp. 415-420, 1984.

5. M. Mahalingam and J. Andrews. High Performance Air Cooling for Microelectronics, Procs. Int. Symp. on Cooling Technology for Electronic Equipment, Honolulu, HI, pp. 608-625, 1987.

6. R. J. Phillips, L. R. Glicksman, and R. Larson. Forced Convection, Liquid-Cooled, Microchannel Heat Sinks for High-Power-Density Microelectronics, Procs. Int. Symp. Cooling Technology for Electronic Equipment, Honolulu, HI, pp. 227-248, 1987.

7. J. Pfahler, J. Harley, H. H. Bau, and J. Zemel. Liquid Transport in Micron and Submicron Channels, J. Sensors Actuators A, vol. 21-23, pp. 431-434, 1990.

8. T. L. Hoopman. Microchanneled Structures, Microstruct., Sensors Actuators, ASME DSC-108, pp. 171-174, 1990.

9. S. B. Choi, R. F. Barron, and R. O. Warrington. Fluid Flow and Heat Transfer in Microtubes, Micromech. Sensors, Actuators Syst., ASME DSC-Vol.32, pp. 123-134, 1991.

10. M. M. Rahman and F. Gui. Experimental Measurements of Fluid Flow and Heat Transfer in Microchannel Cooling Passages in a Chip Substrate, Adv. Electron. Packaging, ASME EEPVol. 4-2, pp. 685-692. 
11. X. F. Peng and B. X. Wang. Forced Convection and Flow Boiling Heat Transfer for Liquid Flowing through Microchannels, Int. J. Heat Mass Transfer, vol. 14, pp. 3421-3427, 1993.

12. B. X. Wang and X. F. Peng. Experimental Investigation on Liquid Forced Convection Heat Transfer through Microchannels, Int. J. Heat Mass Transfer, vol. 37, suppl. 1, pp. 73-82, 1994.

13. X. F. Peng, G. P. Peterson, and B. X. Wang. Frictional Flow Characteristics of Water Flowing through Microchannels, Exp. Heat Transfer, vol. 7, pp. 249-264, 1994.

14. X. F. Peng, G. P. Peterson, and B. X. Wang. Heat Transfer Characteristics of Water Flowing through Microchannels, Exp. Heat Transfer, vol. 7, pp. 265-283, 1994.

15. X. F. Peng and G. P. Peterson. The Effect of Thermofluid and Geometrical Parameters on Convection of Liquids Through Rectangular Microchannels, Int. J. Heat Mass Transfer, vol. 38, pp. 755-758, 1995.

16. X. F. Peng and G. P. Peterson. Convective Heat Transfer and Flow Friction for Water Flow in Microchannel Structures, Int. J. Heat Mass Transfer, vol. 39, pp. 2599-2608, 1996.

17. X. F. Peng and G. P. Peterson. Forced Convection Heat Transfer of Single Phase Binary Mixtures through Microchannels, Exp. Thermal Fluid Sci., vol. 12, pp. 98-104, 1996.

18. T. M. Harms, M. Kazmierczak, F. M. Gerner, A. Holke, H. T. Henderson, J. Pilchowski, and K. Baker. Experimental Investigation of Heat Transfer and Pressure Drop through Deep Microchannels in a (110) Silicon Substrate, ASME HTD-Vol.351-1, pp. 347-357, 1997.

19. Y. Zhuang, C. F. Ma, and M. Qin. Experimental Study on Local Heat Transfer with Liquid Impingement Flow in Two-Dimensional Micro-Channels, Int. J. Heat Mass Transfer, vol. 40, pp. 4055-4059, 1997.

20. T. M. Adams, S. I. Abdel-Khalik, S. M. Jeter, and Z. H. Qureshi. An Experimental Investigation Of Single-Phase Forced Convection in Microchannels, Int. J Heat Mass Transfer, vol. 41, pp. 851-857, 1998.

21. T. M. Adams, M. F. Dowling, S. I. Abdel-Khalik, and S. M. Jeter. Applicability of Traditional Turbulent Single Phase Forced Convection Correlations to Non-Circular Microchannels, Int. J. Heat Mass Transfer, vol. 42, pp. 4411-4415, 1999.

22. C. P. Tso and S. P. Mahulikar. Use of the Brinkman Number for Single Phase Forced Convective Heat Transfer in Microchannels, Int. J. Heat Mass Transfer, vol. 41, pp. 1759-1769, 1998.

23. C. P. Tso and S. P. Mahulikar. Role of the Brinkman Number in Analyzing Flow Transitions in Microchannels, Int. J. Heat Mass Transfer, vol. 42, pp. 1813-1833, 1999.

24. C. P. Tso and S. P. Mahulikar. Experimental Verification of the Role of Brinkman Number in Microchannels Using Local Parameters, Int. J. Heat Mass Transfer, vol. 43, pp. 1837-1849, 2000.

25. H. B. Ma, G. P. Peterson, and X. J. Lu. Influence of Vapor-Liquid Interactions on the Liquid Pressure Drop in Triangular Microgrooves, Int. J. Heat Mass Transfer, vol. 37, pp. 2211-2219, 1994.

26. M. B. Kleiner, S. A. Kuehn, and K. Haberger. High Performance Forced Air Cooling Scheme Employing Microchannel Heat Exchangers, IEEE Trans. Components, Packaging Manuf. Technol. A, vol. 18, pp. 795-804, 1995.

27. K. Takamatsu, N. Fujimoto, Y. F. Rao, and K. Fukuda. Numerical Study of Flow and Heat Transfer of Superfluid Helium in Capillary Channels, Cryogenics, vol. 37, pp. 829-835, 1997.

28. D. Copeland, M. Behnia, and W. Nakayama. Manifold Microchannel Heat Sinks: Isothermal Analysis, IEEE Trans. Components, Packaging, Manuf. Technol. A, vol. 20, pp. 96-102, 1997.

29. G. M. Mala, D. Li, and J. D. Dale. Heat Transfer and Fluid Flow in Microchannels, Int. J. Heat Mass Transfer, vol. 40, pp. 3079-3088, 1997.

30. G. M. Mala, D. Li, C. Werner, H. J. Jacobasch, and Y. B. Ning. Flow Characteristics of Water through a Microchannel between Two Parallel Plates with Electrokinetic Effects, Int. J. Heat Fluid Flow, vol. 18, pp. 489-496, 1997. 
31. C. Yang, D. Li, and J. H. Masliyah. Modeling Forced Liquid Convection in Rectangular Microchannels with Electrokinetic Effects, Int. J. Heat Mass Transfer, vol. 41, pp. 4229-4249, 1998.

32. H. H. Bau. Optimization of Conduits' Shape in Microscale Heat Exchangers, Int. J. Heat Mass Transfer, vol. 41, pp. 2717-2723, 1998.

33. D. Y. Lee and K. Vafai. Comparative Analysis of Jet Impingement and Microchannel Cooling for High Heat Flux Applications, Int. J. Heat Mass Transfer, vol. 42, pp. 1555-1568, 1999.

34. E. B. Arkilic, K. S. Breuer, and M. A. Schmidt. Gaseous Flow in Microchannels, Application of Microfabrication to Fluid Mechanics, ASME FED-Vol. 197, pp. 57-66, 1994.

35. E. B. Arkilic, M. A. Schmidt, and K. S. Breuer. Gaseous Slip Flow in Long Microchannels, IEEE J. Microelectromech. Syst., vol. 6, pp. 167-178, 1997.

36. D. Yu, R. Warrington, R. Barron, and T. Ameel. An Experimental and Theoretical Investigation of Fluid Flow and Heat Transfer in Microtubes, ASME/JSME Thermal Eng. Conf., vol. 1, pp. 523-530, 1995.

37. C. Mavriplis, J. C. Ahn, and R. Goulard. Heat Transfer and Flow Fields in Short Microchannels Using Direct Simulation Monte Carlo, AIAA J. Thermophys. Heat Transfer, vol. 11, pp. 489496, 1997.

38. J. Pfahler, J. Harley, H. H. Bau, and J. Zemel. Gas and Liquid Flow in Small Channels, Micromech. Sensors, Actuators Syst., ASME DSC-32, pp. 49-60, 1991.

39. H. P. Kavehpour, M. Faghri, and Y. Asako. Effects of Compressibility and Rarefaction on Gaseous Flows in Microchannels, Numer. Heat Transfer A, vol. 32, pp. 677-695, 1997.

40. Z. Y. Guo and X. B. Wu. Compressibility Effect on the Gas Flow and Heat Transfer in a Micro Tube, Int. J. Heat Mass Transfer, vol. 40, pp. 3251-3254, 1997.

41. C. S. Chen, S. M. Lee, and J. D. Sheu. Numerical Analysis of Gas Flow in Microchannels, Numer. Heat Transfer A, vol. 33, pp. 749-761, 1998.

42. Y. Y. Niu. Navier-Stokes Analysis of Gaseous Slip Flow in Long Grooves, Numer. Heat Transfer A, vol. 36, pp. 75-93, 1999.

43. M. B. Bowers and I. Mudawar. Two Phase Electronic Cooling Using Mini-channel and Microchannel Heat Sinks. Part 1: Design Criteria and Heat Diffusion Constraints, ASME J. Electron. Packaging, vol. 116, pp. 290-297, 1994.

44. M. B. Bowers and I. Mudawar. Two Phase Electronic Cooling Using Mini-channel and Microchannel Heat Sinks. Part 2: Flow Rate and Pressure Drop Constraints, ASME J. Electron. Packaging, vol. 116, pp. 298-305, 1994.

45. M. B. Bowers and I. Mudawar. High Flux Boiling in Low Flow Rate, Low Pressure Drop Mini-channel and Micro-channel Heat Sinks, Int. J. Heat Mass Transfer, vol. 37, pp. 321-332, 1994.

46. X. F. Peng, B. X. Wang, G. P. Peterson, and H. B. Ma. Experimental Investigation of Heat Transfer in Flat Plates with Rectangular Microchannels, Int. J. Heat Mass Transfer, vol. 38, pp. 127-137, 1995.

47. X. F. Peng, G. P. Peterson, and B. X. Wang. Flow Boiling of Binary Mixtures in Microchannel Plates, Int. J. Heat Mass Transfer, vol. 39, pp. 1257-1264, 1996.

48. X. F. Peng, H. Y. Hu, and B. X. Wang. Flow Boiling through V-shape Microchannels, Exp. Heat Transfer, vol. 11, pp. 87-90, 1998.

49. J. M. Ha and G. P. Peterson. The Interline Heat Transfer of Evaporating Thin Films along a Micro Grooved Surface, ASME J. Heat Transfer, vol. 118, pp. 747-755, 1996.

50. J. M. Ha and G. P. Peterson. Capillary Performance of Evaporating Flow in Microgrooves-An Analytical Approach for Very Small Tilt Angles, ASME J. Heat Transfer, vol. 120, pp. 452457, 1998.

51. G. M. Roach, Jr., S. I. Abdel-Khalik, S. M. Ghiaasiaan, M. F. Dowling, and S. M. Jeter. LowFlow Critical Heat Flux in Heated Microchannels, Nuclear Sci. Eng., vol. 131, pp. 411-425, 1999. 
52. G. P. Celata, M. Cumo, and A. Mariani. Burnout in Highly Subcooled Water Flow Boiling in Small Diameter Tubes, Int. J. Heat Mass Transfer, vol. 36, pp. 1269-1285, 1993.

53. R. Mertz, A. Wein, and M. Groll. Experimental Investigation of Flow Boiling Heat Transfer in Narrow Channels, Heat Technol., vol. 14, pp. 47-54, 1996.

54. J. C. Sturgis and I. Mudawar. Critical Heat Flux in a Long, Rectangular Channel Subjected to One-Sided Heating-I. Flow Visualization, Int. J. Heat Mass Transfer, vol. 42, pp. 1835-1847, 1999.

55. J. C. Sturgis and I. Mudawar. Critical Heat Flux in a Long, Rectangular Channel Subjected to One-Sided Heating-II. Analysis of Critical Heat Flux Data, Int. J. Heat Mass Transfer, vol. 42, pp. 1849-1862, 1999.

56. J. M. Cuta, C. E. McDonald, and A. Shekarriz. Forced Convection Heat Transfer in Parallel Channel Array Microchannel Heat Exchanger, Advances in Energy Efficiency, Heat/Mass Transfer Enhancement, ASME PID-Vol.2/HTD-Vol. 338, pp. 17-23, 1996.

57. T. S. Ravigururajan. Impact of Channel Geometry on Two Phase Flow Heat Transfer Characteristics of Refrigerants in Microchannel Heat Exchangers, ASME J. Heat Transfer, vol. 120, pp. 485-491, 1998.

58. K. A. Triplett, S. M. Ghiaasiaan, S. I. Abdel-Khalik, and D. L. Sadowski. Gas-Liquid Two Phase Flow in Microchannels. Part I: Two Phase Flow Patterns, Int. J. Multiphase Flow, vol. 25, pp. 377-394, 1999.

59. K. A. Triplett, S. M. Ghiaasiaan, S. I. Abdel-Khalik, A. LeMouel, and B. N. McCord. GasLiquid Two Phase Flow in Microchannels. Part II: Void Fraction and Pressure Drop, Int. J. Multiphase Flow, vol. 25, pp. 395-410, 1999.

60. J. W. Coleman and S. Garimella. Characterization of Two-Phase Flow Patterns in Small Diameter Round and Rectangular Tubes, Int. J. Heat Mass Transfer, vol. 42, pp. 2869-2881, 1999.

61. D. B. Tuckerman. Heat Transfer Microstructures for Integrated Circuits, Ph.D. thesis, Stanford University, Stanford, CA, 1984.

62. A. Weisberg, H. H. Bau, and J. Zemel. Analysis of Microchannels for Integrated Cooling, Int. J. Heat Mass Transfer, vol. 35, pp. 2465-2474, 1992.

63. S. K. Roy and B. L. Avanik. Very High Heat Flux Microchannel Heat Exchanger for Cooling of Semiconductor Laser Diode Arrays, IEEE Trans. Components, Packaging Manuf. Technol. B: Adv. Packaging, vol. 19, pp. 444-451, 1996.

64. A. Aranyosi, L. M. R. Bolle, and H. A. Buyse. Compact Air-Cooled Heat Sinks for Power Packages, IEEE Trans. Components, Packaging Manuf. Technol. A, vol. 20, pp. 442-451, 1997.

65. C. Perret, C. Schaeffer, and J. Boussey. Microchannel Integrated Heat Sinks in Silicon Technology, IEEE Industry Applications Society Annual Meeting, Vol. 2, 98CH36242, pp. 1051-1055, 1998.

66. C. Gillot, C. Schaeffer, and A. Bricard. Integrated Micro Heat Sink for Power Multichip Module, IEEE Industry Applications Society Annual Meeting, Vol. 2, 98CH36242, pp. 10461050, 1998.

67. C. Gillot, L. Meysenc, and C. Schaeffer. Integrated Single and Two Phase Micro Heat Sinks under IGBT Chips, IEEE Trans. on Components Packaging Technol., vol. 22, pp. 384-389, 1999.

68. S. Yu, T. Ameel, and M. Xin. An Air-Cooled Microchannel Heat Sink with High Heat Flux and Low Pressure Drop, Proc. 33rd Natl. Heat Transfer Conf., Albuquerque, NM, pp. 1-7, 1999.

69. M. Richter, P. Woias, and D. Weiss. Microchannels for Applications in Liquid Dosing and Flow-Rate Measurement, Sensors Actuators A, vol. 62, pp. 480-483, 1997.

70. C. D. Meinhart, S. T. Wereley, and J. G. Santiago. PIV Measurements of a Microchannel Flow, Exp. Fluids, vol. 27, pp. 414-419, 1999.

71. V. Gnielinski. New Equations for Heat and Mass Transfer in Turbulent Pipe and Channel Flow, Int. Chem. Eng., vol. 16, pp. 359-368, 1976. 